\title{
XIX. An account of some experiments with the torsion-rod, for determining the mean density of the earth
}

Francis Baily Esq. F.R.S.

To cite this article: Francis Baily Esq. F.R.S. (1842) XIX. An account of some experiments with the torsion-rod, for determining the mean density of the earth , Philosophical Magazine Series 3, 21:136, 111-121, DOI: 10.1080/14786444208621495

To link to this article: http://dx.doi.org/10.1080/14786444208621495

曲 Published online: 01 Jun 2009.

Submit your article to this journal $[\pi$

Џll Article views: 1

Q View related articles $\sqsubset$ 
(Gerber's Anatomy, p. 31); some of the corpuscles, just like misshapen blood-discs, are seen on their edges; others appear mottled, and one exhibits three nuclei. Many minute circular molecules are seen in the fibrine; they were generally from $\overline{30}, \frac{1}{0} 00$ th to ${ }_{15,0 \overline{0}} 0$ th of an inch in diameter, but their appearance has not been at all clearly preserved in the engraving. $B$. The same washed with dilute acetic acid; the nuclei of the corpuscles and the minute molecules are distinctly exhibited. Several of the latter are attached to a corpuscle made very faint by the acid.

In fibrine obtained by washing from the blood of the oviparous vertebrata, there is also frequently an appearance of minute fibrils, as shown at F, in fig. 2; but this fibrine is chiefly characterized by its containing numerous particles similar to and probably identical with the nuclei of the blood corpuscles : these particles may often be seen in the fibrine without the addition of any reagent, and acetic acid renders them very plain, as at $G$ in fig. 2.

XIX. An Account of some Experiments with the Torsionrod, for Determining the Mean Density of the Earth. By Francis Barly, Esq., F.R.S., Vice-President of the Royal Astronomical Society*.

THE author commences his account with a short preliminary history of the subject, and a reference to the previous labours of Maskelyne and Cavendish. He considers the experiments of Maskelyne, on the attraction of the Schehallien mountain, by no means decisive of the question; and with respect to those of Cavendish, by means of the torsion-rod, he is of opinion that Cavendish's object in drawing up his memoir was more for the purpose of exhibiting a specimen of what he considered to be an excellent method of determining this important inquiry, than of deducing a result, at that time, that should lay claim to the full confidence of the scientific world. For, Cavendish himself (who made only 23 experiments), in allusion to this very point, expresses a doubt on the subject, and hints at some further experiments which he had in view, for clearing up some of the irregularities which he had met with. But, as no further account of any subsequent experiments is on record, and as no trace of any new light on this subject can be found amongst Cavendish's papers, the propriety and advantage of repeating the experiments, under

* From the Monthly Notices of the Royal Astronomical Society, having been read May 13 and June 10, 1842. An abstract of Mr. Baily's preliminary paper was given in Phil. Mag. Third Series, vol. xii. p. 233: a notice of M. Menabrea's paper on Cavendish's Experiments will be found in vol. xix. p. 62. A translation of Laplace's memoir on the mean density of the Earth, in which Cavendish's tesults are examined, was communicated by Dr. Hutton to the First Series, vol. lvi. p. 321.-EDIT. 
new circumstances, and with all the improvements of modern artists, had consequently been frequently discussed amongst scientific persons: and in the year 1835 the Council of this Society appointed a Committee for the express purpose of considering the subject. No effective steps, however, were taken even by this body for carrying the measure into execution till the autumn of the year 1837, when Mr. Airy, the Astronomer Royal (one of the Vice-Presidents of this Society), applied for, and obtained from his late Majesty's Government, a grant of 500l. to defray the expenses of this object.

Mr. Baily having offered to undertake the laborious task of making the proposed experiments, and of computing the results, the whole arrangement of the plan, and the entire execution of the work, was placed at his disposal and under his control.

It is somewhat singular, that, whilst this plan was in agitation in this country, a similar course of experiments had been actually undertaken and accomplished by M. Reich, Professor of Natural Philosophy in the Academy of Mines, at Freyberg in Saxony; an account of which was read before the German Scientific Association, which met at Prague in September 1837 ; and an abstract of the results was printed in the Monthly Notices of this Society, for December following*. Though the experiments are, on the whole, in good accordance with the general result obtained by Cavendish, yet they do not interfere with the plan that this Society had in contemplation; which was not merely to repeat the original experiments of Cavendish in a somewhat similar manner, but also to extend the investigation by varying the magnitude and substance of the attracted balls-by trying the effect of different modes of suspension-by adòpting considerable difference of temperature-and by other variations that might be suggested during the progress of the inquiry. Reich made use of one mass only, and that much inferior in weight to the two adopted by Cavendish. The weight of Reich's large ball was little more than 99 pounds avoirdupois; whilst the two spheres, used by Cavendish, weighed nearly 700 pounds. Reich's experiments also were (like Cavendish's) too few in number; 57 only having been made, from which fourteen results have been deduced; the mean of which makes the density of the earth equal to 5•44, almost identical with that of Cavendish.

As a great portion of the apparatus, which had been ordered, was at this time actually completed, and the remainder of it in considerable progress, Mr. Baily resolved to proceed in the

[* This abstract appears in Mr. Baily's preliminary paper, already referred to.-EDIT.] 
inquiry, notwithstanding this apparent confirmation of Cavendish's results. Various places were suggested, by different persons, as the most suitable and fit for performing experiments of this kind: but, after inspecting several situations that were proposed, and considering all the circumstances of the case, Mr. Baily at length decided to carry them on at his own house, which he considers to be not only the most convenient that he could have selected, but which he has since found to be as suitable and fit as any that could have been specially erected for the express purpose. This house stands detached from any other building, in a large garden, some distance from the street, and consists of one story only.

The author then proceeds to give a description of the room in which the experiments were made, and likewise of the apparatus that was constructed for this special purpose. Although the apparatus was in a general view similar to that of Cavendish, yet in some respects it was essentially different. The great balls (or masses, as they are called) were suspended from the ceiling by Cavendish and Reich : but Mr. Baily supported them, from the floor, on a plank which turned on a pivot, and suspended the small balls from the ceiling; thus reversing the mode of operations. This method of moving the masses he considers to be a great improvement: for he says, "Nothing can exceed the ease, the steadiness, and the facility with which these large bodies are moved : and during the many thousands of times that they have been turned backwards and forwards, I have never observed the least deviation from the most perfect accuracy. At the final close of all the experiments, the pivot turns as steadily, as freely, and as accurately as at the commencement of the operations." The small balls were also, by Cavendish and Reich, suspended by a fine wire from the ends of the torsion-rod; whereas Mr. Baily screwed them to the ends of the torsion-rod, of which they thus formed an integral and solid portion. The motion of the torsion-rod was observed by means of a reflected image of the scale, from a small mirror attached to the centre of the torsion-rod, in the manner proposed by Gauss in magnetical experiments*, and adopted by Reich. Some other alterations were likewise made in the construction and arrangement of the apparatus, to which it is unnecessary to allude more minutely on the present occasion.

Mr. Baily made use occasionally of several small balls, of different sizes, and formed of different substances, with a view

[* See Phil. Mag. Third Series, vol. ii. p. 296 : also Taylor's Scientific Memoirs, vol. ii. p. 31,-EDrT.]

Phil. Mag. S. 3. Vol. 21. No. 136. Aug. 1842. 
of ascertaining whether the results would be affected by such a variation: these were platina, lead, zinc, glass, ivory, and hollow brass, varying from $1 \frac{1}{2}$ inch to $2 \frac{1}{2}$ inches in diameter. The mode of suspension was also diversified, with a similar view : iron, copper, brass, and silk were successively. used, not only single, but also double, similar to the bifilar mode suggested by Gauss* for certain magnetical experiments. The mean weight of each of the great balls (or masses) was $2,663,282$ grains, or about $380 \frac{1}{2}$ pounds avoirdupois, as determined by the accurate weights and scales of the Bank of England. And the weight of each of the small balls varied from 1950 to 23,742 grains. The length of the suspensionline was 60 inches; and the length of the torsion-rod (between the centres of the two balls affixed thereto) was nearly : 80 inches. The torsion-rod was made of fine deal, of an uniform shape throughout its whole length, and weighed only about 2300 grains. Another torsion-rod was afterwards made, for some special experiments, the weight of which was nearly ten times as great : it consisted of a solid brass rod, and was occasionally used without any balls attached to the ends.

The torsion-rod and the suspension-lines were screened by a mahogany box, constructed exactly similar in form to that used by Cavendish, but supported from the ceiling in a very firm manner, and unconnected with the floor or any other part of the surrounding apparatus. Every precaution was taken to secure the torsion-rod from the influence of any sudden or partial change of temperature; and also to insure the stability and firmness of the support to which it was attached. The author's remarks on this subject are worthy of notice: for he says, "In order to satisfy myself on this point, at the time of the original construction of the apparatus, I made various attempts to create a sensible disturbance in the motion of the torsion-rod, by causing the doors to be frequently and violently slammed-by junping heavily on the floor of the room-and also above the ceiling-and in other different ways, having a similar tendency; but in no instance could I observe the least effect upon the lateral motion of the rod. I have also frequently tried the same experiment, when dif. ferent visitors were present, since the apparatus has been completed; and have moreover many times not only accidentally, but also designedly, made a regular series of experiments for determining the density of the earth, during the most violent storms that I have ever witnessed, when the wind has been so boisterous, and blowing in such gusts, that the house has been

[* See Taylor's Scientific Memoirs, vol. ii. p. 252.-EDrr.] 
shaken to its centre. But in no instance have I ever seen the least disturbance in the lateral motion of the torsion-rod, nor any difference produced in the results of the experiments. I have thought it proper to make these remarks and thus to place them on record, because some persons at first hazarded an opinion that the place which I had selected might not be quite adapted for experiments of so delicate a nature. But a moment's consideration will convince a person conversant with the subject, that no dancing motion of the suspensionline (even if it did exist) would tend to produce an irregular lateral or angular motion in the torsion-rod; and this is the only anomalous motion we need guard against.

" There is also another remarkable circumstance connected with this subject, which I think it requisite likewise here to place on record. When the torsion-rod has been in a state of repose, I have frequently shaken the torsion-box, by rapidly moving the ends backward and forward from side to side fifty or sixty times, and even more: but I could never discover that this disturbance of the box caused the least motion in the torsion-rod, which still retained its stationary position. This experiment bas been witnessed at various times by several scientific persons. Yet, notwithstanding this torpid state of the torsion-rod, if the slightest change of temperature be applied near the side of the torsion-box, or if either side near the balls be sprinkled with a little spirit of wine, the torsion-rod is immediately put in motion and the resting-point undergoes a rapid change."

Notwithstanding these favourable circumstances the author at first met with certain irregularities and discordances, which he found it difficult to remove; and which appear to have been experienced also by Cavendish and Reich,-caused, as it is presumed, by variations in the temperature of the room in which the experiments were carried on. Cavendish chose an out-house in his garden at Clapham Common; and, having constructed his apparatus reithin the building, he moved the masses by means of ropes passing through a hole in the wall, and observed the torsion-rod, by means of a telescope fixed in an ante-room on the outside. The general temperature of the interior was therefore probably uniform during the time that he was occupied in any one set of experiments: but it is scarcely to be expected that a building of this kind, and in such a situation, would preserve the same uniform temperature for twenty-four successive hours; especially at the season which he selected for his operations. Reich pursued a similar plan, but under circumstances apparently more favourable; for he selected a dark cellar, where the temperature was not I 2 
so likely to be disturbed: and, having closed up the door, he adopted Cavendish's plan of observing the motions of the torsion-rod, on the outside. But, even in a situation like this, we must not expect a constant uniformity of temperature for a long period. Neither of these authors, however, has given any information on this subject; both of them, however, met with anomalies for which they could not satisfactorily account: and, although Cavendish suspected the cause of some of those anomalies, yet he does not appear to have applied any remedy for the evil, in any of his subsequent experiments.

Mr. Baily remarks, that his first experiments were tolerably regular, although the results were generally greater than those obtained either by Cavendish or Reich; but that he soon observed discrepancies which convinced him that some disturbing force was in operation, which he had not yet contemplated, and which he could not discover. One of the most striking evidences of such anomaly was the remarkable circumstance, that the arc of vibration, during one and the same experiment, would seldom decrease in the regular manner which it ought to pursue, if the torsion-rod were guided by an uniform influence; and moreover, that in fact it would frequently increase, contrary to all the known laws of bodies so circumstanced. Notwithstanding these interruptions, he not only considered it proper to continue the experiments, for some time, in the usual manner, in the hope that he might thereby eventually throw some light on the probable cause of the anomalies, and perhaps be enabled to apply a correction for the effect of their influence; but also was induced to institute several new courses of experiments, as circumstances and suggestions occurred, for the express purpose of elucidating the subject. The theories of electricity, magnetism, temperature, and currents of air-the infuence of different modes of suspension by single and double wires and by double silk lines - the trial of balls composed of different substances and magnitudes - were successively and frequently appealed to, and various experiments made to discover their probable effect on the results. The mode of conducting the experiments was also varied in different ways, with a view of eliciting information on the point in question. Some of them were carried on like those of Cavendish, and others like those of Reich (for the methods of these two experimentalists were very different from each other), whilst many more were conducted on a plan essentially different from either of them. Heated balls and powerful lamps were occasionally applied near the torsionbox, with a view to raise an artificial temperature, and thus create a powerful influence; and, op the other hand, masses 
of ice have been employed for a similar purpose. The manner likewise of putting the masses in motion was frequently diversified, under the hope of being enabled thereby to obtain a clue to the object of research. But the author has considered it needless to proceed with a detail of these fruitless operations, which were carried on, without much interruption, for upwards of eighteen months, and amounted in number to nearly 1300 experiments. Many of these were of a mere speculative nature, with a view to discover the cause of the anomalies here alluded to; but a thousand of them, at least, were more especially made for the purpose of determining the density of the earth, and were eventually reduced. But the results, although in many cases very consistent amongst themselves, were upon the whole so discordant and unsatisfactory, that no confidence could be placed on the general result, as a correct value of the true object of inquiry. And, as he had pre-determined not to select merely those experiments which might appear to be the most favourable specimens, or supporting any particular theory, and to keep out of view and reject the rest, he consequently abandoned the whole.

During these investigations the author was frequently visited by several scientific persons who took a lively interest in the pursuit in which he was engaged, and who kindly offered him their opinion and advice on several occasions. But he remarks, that he was principally indebted to Professor Forbes of Edinburgh, for the most satisfactory removal of the principal anomalies that he had met with. This gentleman's intimate acquaintance with the theory of heat, and its various operations, effects, and influence, led him to agree with Cavendish in opinion, that one source, at least, of the anomalies might arise from the radiation of heat from the masses, when they were brought up to the sides of the torsion-box: and that this might even still operate notwithstanding the interposition of the sides of the box, and the precautions already taken. As a remedy for this influence he suggested the propriety of having the masses gilt, and also of procuring a gilt case, as a cover to the torsion-box, for the purpose of preventing the effect of radiation, from whatever source it might arise. Acting upon this advice, Mr. Baily not only caused a gilt case to be made in the manner here proposed, but also caused the torsion-box itself to be previously covered, all over, with thick flannel. These and other alterations and improvements having been completed, the author resolved to commence a nere series of experiments, that were likely to be thus made under more favourable auspices, for the correct determination of the mean density of the earth: and it appears 


\section{Mr. Baily's Experiments with the Torsion-rod}

that the results soon convinced him that the proper mode had been taken for the removal of the principal source of discordance. For although, in some cases, slight discrepancies may still appear to exist, as might be expected in any inquiry that involves so delicate a system of operations, yet where the discordances are of greater magnitude they seem to be confined to one class of experiments, and to depend principally on the nature and construction of the material of which the suspension-line or torsion-rod is composed, and do not materially affect the general result of the whole. In fact, $\mathrm{Mr}$. Baily states that he has since met with very few experiments, made in the regular mode of proceeding, that are objectionable, or that need be rejected. Every experiment therefore that has been made, under this new arrangement of the apparatus (whether good, bad, or indifferent), has been recorded and preserved; and they are all given without any reserve whatever; it being left to the reader himself to reject or retain, at his pleasure, such as he may think fit.

After these introductory remarks, the author proceeds to the several modes of carrying on the regular system of operations which he had undertaken. With respect to the torsionrod, he states that it is never at absolute rest, but is constantly in a state of vibration on its centre; and consequently when the end of it is viewed at a distance with the telescope, it appears to oscillate on each side of a mean point, called the resting-point. For, even when it is apparently in a state of complete repose, minute vibrations are always perceptible with the telescope ; and the times of performing such infinitesimal arcs correspond, in most cases, very nearly with the mean time of vibration that takes place when the torsion-rod is in full action. Mr. Baily however observes, that this resting-point is by no means permanent or stationary, and seldom remains in the same position for any length of time, even when the torsion-rod is not influenced by the approach of the masses. The extent and direction of its disturbance, as well as its rate of motion when so disturbed, are very variable, and seem to depend on causes which have not been sufficiently accounted for, but which may in some measure arise either from slight changes of temperature, or some latent alteration in the component parts of the suspension-line. These vibratory motions of the resting-point (which must be carefully distinguished from the regular vibratory changes in the position of the torsion-rod itself, caused by the near approach of the masses) do not materially affect the mean results in a series of experiments ; more especially if their march be regular. It is only when any sudden and considerable transition takes place, that 
a sensible and material error is likely to occur: but this seldom happens if due precaution has been taken to screen the torsion-box effectually. Yet the author is still of opinion that discordances sometimes arise which cannot wholly be attributed to change of temperature, but to some other occult influence with which we are at present unacquainted. The regular march of the resting-point of the torsion-rod is one of the most important objects of attention; since any considerable deviation therefrom is the source of great discordance, and therefore requires to be watched with care.

The torsion force comes next under consideration. $\mathrm{Mr}$. Baily justly remarks that the torsion force of a wire is that elastic power in the body, by means of which it is enabled to return to its original position, after being drawn aside by any external impulse. It varies with the substance, magnitude, and length of the wire; but it is generally considered to be constant for the same wire, whatever be the weight suspended thereto. This, however, must be taken within certain limits, since the time of vibration (which is one of the elements for determining the force of torsion). will frequently differ very considerably without any apparent or sensible alteration in the component parts of the apparatus. For the author states that we frequently have in the same hour very considerable variations in the time of vibration, which evidently show that the force of torsion has undergone some sensible change. But this alteration in the torsion force does not appear to affect the results of the experiments, since we find that, when the time increases, the deviation is also increased in due proportion. The magnitude, therefore, of the force of torsion is not a necessary object of inquiry in these investigations.

The only two objects requiring close attention, for the purpose of obtaining results from any of the experiments, are the determination of the mean resting-point of the torsion-rod, and the time of its vibration. Now, it fortunately happens that these two objects can, in all cases, be observed with the greatest ease and accuracy, however anomalous they may be; and they are never accompanied with any doubt or difficulty. There is however another subject that is required also to be accurately ascertained in every experiment; namely, the exact distance of the centre of the masses from the centre of the balls. This has been effected by means of plumb-lines, which abut against the masses, and the distances between which are measured, at every experiment, by means of a microscopical apparatus, carefully adjusted.

From the results of the several experiments that the author has made, it would appear that single wires, of different dia- 
meters, give slight differences in the results. But, he states that the most discordant results occur where the double suspension-lines are formed of silk; and he apprehends that these anomalies have arisen from the circumstance that all the fibres, of which the skein is composed, are not equally stretched by the different balls as they are successively attached to the torsionrod; and that they are thus severally operated on by different forces, which consequently produces a discordancy in the results. These discordances, however, appear to be generally confined within certain limits.

The author then gives a detailed account of the various experiments that he has made, under the improved form of apparatus, which amount in the whole to 2153 ; and which were pursued and conducted in different ways, for the purpose of throwing some light on the slight discrepancies that, in spite of his care and caution, would occasionally intrude themselves. It would be impossible in an abstract like this to give a minute detail of the several modes that were adopted in carrying on these operations, and which must therefore be left unexplained till the work itself is published. But the following short synoptical view will enable the reader to form an estimate of the general results obtained from the different balls, according to the manner in which they have been successively suspended. The seven different balls employed are arranged, in the first column, in the order of their weight; and the number of experiments made therewith, together with the mean resulting density therefrom, is classed in the three collateral columns, according as the suspension was formed of double silk lines, double metal wire, or single copper wire. The three detached series, at the bottom of the table, containing 149 experiments, will be presently explained.

\begin{tabular}{|c|c|c|c|c|c|c|}
\hline \multirow{2}{*}{ Balls. } & \multicolumn{2}{|c|}{ Double silk. } & \multicolumn{2}{|c|}{ Double wire. } & \multicolumn{2}{|c|}{ Single wire. } \\
\hline & No. & Density & No. & Density. & No. & Density. \\
\hline 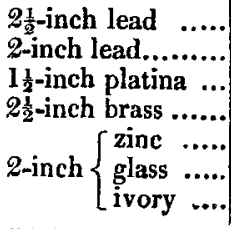 & $\begin{array}{r}148 \\
218 \\
89 \\
46 \\
162 \\
158 \\
99\end{array}$ & $\begin{array}{l}5 \cdot 60 \\
5 \cdot 65 \\
5 \cdot 66 \\
5 \cdot 72 \\
5 \cdot 73 \\
5 \cdot 78 \\
5 \cdot 82\end{array}$ & $\begin{array}{c}130 \\
145 \\
\cdots \\
\ldots \\
20 \\
170 \\
162\end{array}$ & $\begin{array}{c}5 \cdot 62 \\
5 \cdot 66 \\
\ldots \\
\ldots \\
5 \cdot 68 \\
5 \cdot 71 \\
5 \cdot 70\end{array}$ & $\begin{array}{r}57 \\
162 \\
86 \\
92 \\
40 \\
\ddot{20}\end{array}$ & $\begin{array}{c}5 \cdot 58 \\
5 \cdot 59 \\
5 \cdot 56 \\
5 \cdot 60 \\
5 \cdot 61 \\
\ldots . . \\
5 \cdot 79\end{array}$ \\
\hline \multicolumn{3}{|c|}{$\begin{array}{l}2 \frac{1}{2} \text {-inch lead, with brass rod....... } \\
2 \text {-inch lead, with brass rod } \ldots . . . . \\
\text { Brass rod, alone }\end{array}$} & $\begin{array}{l}44 \\
49 \\
56\end{array}$ & $\begin{array}{l}\mathbf{5 . 6 2} \\
\mathbf{5 . 6 8} \\
\mathbf{5 . 9 7}\end{array}$ & & \\
\hline
\end{tabular}

It cannot be supposed, amongst such a number of experi- 
ments, prosecuted in such a variety of ways and with such different materials, that the several mean results, obtained from the individual classifications, can be of equal weight. In fact, the author himself has, in his investigations of the subject, clearly shown that some of them are entitled to more confidence than others; and moreover that, in a few instances, there may be a fair cause for rejection. On these points however there is no room for explanation in this place: and it may be sufficient here to state, that, assuming every experiment to be of equal weight, the mean result of the whole 2004 experiments is 5.67 . Nor is there much probability that the result of this immense number of experiments will be materially altered, even if those few experiments, which may appear to be affected with some source of error or discordance, should be wholly omitted.

The author remarks that it cannot escape observation that the general mean result, obtained from these experiments, is much greater (equal to $\frac{1}{25}$ th part) than that deduced either by Cavendish or Reich, who both agreed in the very same quantity, namely, $5 \cdot 4.4$ : but he does not assign any probable cause for this discordance. It is evident, however, from the detail which he has given of his own experiments, that perceptible differences not only arose according to the mode in which the torsion-rod was suspended, but also depended on the materials of which the suspension-lines were formed : but it is somewhat singular that none of the mean results, in any of these classifications, are so low as that obtained by the two experimentalists above mentioned.

In these remarks, no notice has yet been taken of the remaining 149 experiments that have been made with the brass torsion-rod; a class of experiments that were undertaken for the express purpose of ascertaining the effect of such a measure on the general result. This torsion-rod was nearly of the same weight as the two 2-inch lead balls, and about half the weight of the two $2 \frac{1}{2}$-inch lead balls. The experiments were made not only witheach of these balls successively attached to the rod, but also with the rod alone, without anything attached thereto. The results show that the attraction of the masses on the rod should be diminished about $\frac{1}{20}$ th part, in order to render these three several results consistent with each other, and also accordant with the same balls and the same mode of suspension, attached to the lighter wooden torsion-rods. 